\title{
Sayed M. Qaim wins the George Hevesy award of the Journal of Radioanalytical and Nuclear Chemistry
}

\author{
Tibor Braun
}

Received: 9 March 2010/Published online: 8 April 2010

(c) Akadémiai Kiadó, Budapest, Hungary 2010

The Editorial Board and the Publishers of the Journal of Radioanalytical and Nuclear Chemistry are glad to announce that the 2008 George Hevesy Medal has been awarded to Professor Sayed M. Qaim for his distinguished contributions to the journal's field.

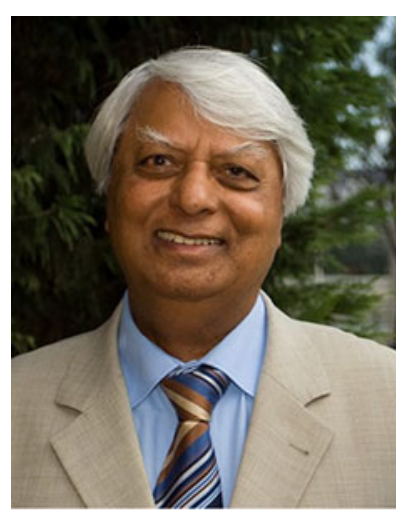

Professor Sayed M. Qaim

T. Braun $(\bowtie)$

Institute of Chemistry, Eötvös Loránd University, Budapest, Hungary

e-mail: braun@mail.iif.hu 